\title{
Differential effects on lever choice and response rate produced by d-amphetamine
}

\author{
D. M. KUHN, I. GREENBERG*, and J. B. APPEL \\ University of South Carolina, Columbia, S.C. 29208
}

Six rats were trained to discriminate between $1.0 \mathrm{mg} / \mathrm{kg}$ of d-amphetamine and saline using a two-lever choice procedure. The threshold for amphetamine discriminability was then determined by gradually lowering the drug dose. Following a dose of $0.25 \mathrm{mg} / \mathrm{kg}$ of d-amphetamine, rats responded about equally often on the saline and the drug levers, but their overall response rates remained elevated well above saline rates.

It is well established that numerous drugs can function as (internal) discriminative stimuli controlling various behaviors (e.g., Overton, 1971, 1973; Kubena \& Barry, 1969). Among these drugs, amphetamine has been shown to be easily discriminated from saline using both lever choice and response patterning procedures (Harris \& Balster, 1968, 1971).

The present study was designed to determine the relationship between the threshold of discriminibility of amphetamine (from no drug) and changes in rate of responding known to be induced by the drug (an unconditioned behavioral effect). If the discriminative and unconditioned properties of amphetamine varied together, then, as discriminability deteriorates with decreasing amphetamine dosage, amount of drug-induced change in response rate should decrease simultaneously.

\section{METHOD}

Subjects

The Ss were 90-day-old experimentally naive male rats of Sprague-Dawley strain. Throughout the study they were housed in individual home cages with ad lib food. They were maintained at $80 \%$ body weight by restricting water intake to $5 \mathrm{~min}$ per day.

\section{Apparatus}

The animals were trained and tested in a standard two-lever box (LVE 1316) contained in a soundproof ventilated outer enclosure. Each reinforcement consisted of $0.10 \mathrm{ml}$ of water; electromechanical programming and recording equipment were located in an adjoining room.

\section{Procedure}

All rats were trained to perform at stable rates on a tandem variable interval 1 -min fixed ratio 10 (Tand VI 1 FR 10) schedule with a reset (punishment) contingency added to the FR component. Rats were first shaped to respond on a CRF schedule on one liver, and then on the other with the first lever covered. On any given day, one lever was covered by a metal plate while the other lever was available. Simultaneously, the reinforcement requirement was gradually raised from CRF to FR 10. The VI schedule was then introduced such that the

*Supported by PHS Post-Doctoral Research Fellowship 6 FO2 DA 54298, from the National Institute of Mental Health. Sponsored by Ernest Furchtgott, who takes full editorial responsibility for its contents. animal eventually had to emit 10 responses after an average interval of $1 \mathrm{~min}$ had elapsed to obtain reinforcement (Tand VI 1 FR 10).

Finally, a punishment contingency was added to the FR 10 segment in order to prevent superstitious chaining from the incorrect to the correct lever. Thus, following each VI 1, 10 correct responses in a row were necessary for reinforcement. An incorrect response during the FR sequence reset the stepper so that another 10 responses on the correct lever were required for reinforcement. Both levers were available to the rat only when drug training was begun.

To determine the discriminative threshold of d-amphetamine, a $1.0-\mathrm{mg} / \mathrm{kg}$ dose was compared with an equal volume of saline. On any day, the rats were injected intraperitoneally (IP) with either drug or saline in random order, and returned to their home cages for $1 / 2 \mathrm{~h}$. They were then placed in the test cage, where responding on either the right or the left lever was reinforced, depending on whether the drug or saline had been administered. This daily training was carried out until stable drug- and saline-related lever choice was observed; thereafter, either training (30 min of Tand VI 1 FR 10) or testing (5 min of extinction) conditions were in effect. At least 2 days of retraining with saline or with d-amphetamine were interjected between extinction test days. Doses of d-amphetamine used in testing sessions were $1.00,0.50,0.25,0.125,0.0625$ and 0.00 (saline) $\mathrm{mg} / \mathrm{kg}$. Each rat received each dose at least twice in a randomized order.

\section{RESULTS AND DISCUSSION}

Throughout the study, discriminative control of lever choice was greatest at the training dose $(1.0 \mathrm{mg} / \mathrm{kg})$ and saline. At this concentration, responding was distributed at $88 \%$ and $89 \%$ on the appropriate amphetamine and saline lever, respectively (Fig. 1). Lever choice at intermediate doses varied monotonically with increasing dose and demonstrated a clear generalization gradient (Fig. 1). At $0.25 \mathrm{mg} / \mathrm{kg}$ amphetamine, it can be seen that responding was divided about equally between the amphetamine and saline levers, while at $0.50 \mathrm{mg} / \mathrm{kg}$, $74.5 \%$ of responses were to the amphetamine lever. Thus, the discriminative threshold $(50 \%$ choices on amphetamine side) for amphetamine lay between 0.25 and $0.50 \mathrm{mg} / \mathrm{kg}$.

The response rate following $\mathrm{d}$-amphetamine was at all times higher than that following saline $(29.5 \mathrm{resp} / \mathrm{min})$ even at doses at which the rats responded predominantly on the saline lever (i.e., $0.0625 \mathrm{mg} / \mathrm{kg}$ and $0.125 \mathrm{mg} / \mathrm{kg}$ ). At the threshold dose, where amphetamine and saline levers were chosen equally of ten, amphetamine response rate $(57.1 \mathrm{resp} / \mathrm{min})$ was $27.6 \mathrm{resp} / \mathrm{min}$ above the saline rate. Thus, a clear dissociation was seen between rate of responding, which remained elevated under the drug, and discriminability, which deteriorated at similar doses.

The results thus indicate that, at least with amphetamine, a drug may continue to exert a strong unconditioned effect while possessing little if any discriminative properties. We have found that this is not 


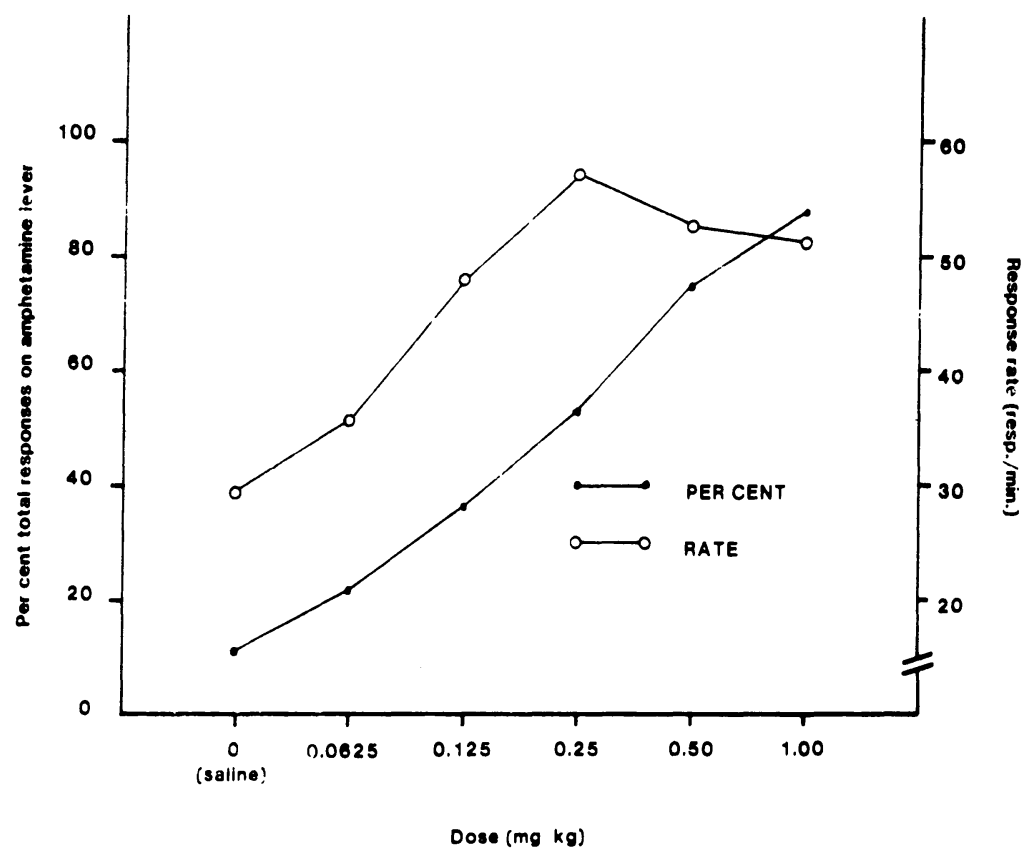

Fig. 1. Mean percent responding on amphetamine lever and mean response rate as a function of dose. $\mathbf{N}=6$.

the case with rate-depressing drugs (LSD, THC, and Pentazocine) where discriminative control is maintained at high levels even after response rate returns to predrug levels. Thus, the present results may apply mainly to rate-increasing (stimulant) drugs such as the amphetamines. The results suggest that a more complete understanding of the behavioral effect of drugs requires that both the discriminative and unconditioned effects be taken into account.

\section{REFERENCES}

Harris, R. T., \& Balster, R. L. Discriminative control by dl-amphetamine and saline of lever choice and response patterning. Psychonomic Science, 1968, 10, 105-106.
Harris, R. T., \& Balster, R. L. An analysis of the function of drugs in the stimulus control of operant behavior. In $T$. Thompson and R. Pickens (Eds.), Stimulus properties of drugs. New York: Appleton-Century-Crofts, 1971.

Kubena, R. K., \& Barry, H. Generalization by rats of alcohol and atropine stimulus characteristics to other drugs. Psychopharmacologia, 1969, 15, 196-206.

Overton, D. A. Discriminative control of behavior by drug states. In T. Thompson and R. Pickens (Eds.), Stimulus properties of drugs. New York: Appleton-Century-Crofts, 1971.

Overton, D. A. State-dependent learning produced by addicting drugs. In S. Fisher and A. M. Freedman (Eds.), Opiate addiction: Origins and treatment. Washington, D.C: Winston, 1073 , in press.

(Received for publication October $24,1973$. ) 